\section{Tropical Journal of Pathology and Microbiology}

\title{
Solid Pseudopapillary Neoplasm of the Pancreas - A rare entity with emphasis on the differential diagnosis.
}

\author{
Khan S. ${ }^{1 *}$, Trisal M. ${ }^{2}$, Husain M. ${ }^{3}$, Khetrapal S. ${ }^{4}$, Hassan M. ${ }^{5}$, Jetley S. ${ }^{6}$ \\ DOI: https://doi.org/10.17511/jopm.2021.i01.10
}

1* Sabina Khan, Professor, Department of Pathology, Hamdard Institute of Medical Sciences and Research, New Delhi, India.

2 Monal Trisal, Demonstrator, Department of Pathology, Hamdard Institute of Medical Sciences and Research, New Delhi, India.

3 Musharraf Husain, Professor and Head of Department, Department of Surgery, Hamdard Institute of Medical Sciences and Research, New Delhi, India.

${ }^{4}$ Shaan Khetrapal, Assistant Professor, Department of Pathology, Hamdard Institute of Medical Sciences and Research, New Delhi, India.

5 Mohd. Jaseem Hassan, Professor, Department of Pathology, Hamdard Institute of Medical Sciences and Research, New Delhi, India.

6 Sujata Jetley, Professor and Head of Department, Department of Pathology, Hamdard Institute of Medical Sciences and Research, New Delhi, India.

Solid Pseudopapillary Neoplasm of Pancreas (SPNP) is a rare, low-grade malignant solid-cystic neoplasm with papillary architecture. It accounts for $2 \%$ to $3 \%$ of pancreatic neoplasms and $0.9 \%$ to $2.7 \%$ of exocrine pancreatic neoplasms. It occurs almost exclusively in young women and has an excellent postsurgical curative rate. Metastasis is rare although it may be locally aggressive. The solid pseudopapillary neoplasm of the pancreas pose a diagnostic challenge both clinically and radiologically as it has a nonspecific clinical presentation with vague radiologic features. Histopathological evaluation and immunohistochemistry remains the gold standard in reaching a definitive diagnosis. Due to its low incidence, the clinical and pathologic features of SPNP have not been extensively studied. We report a case of a 32-year-old lady with solid pseudopapillary neoplasm of the pancreas that was suspected on abdominal CECT as a well-defined mass in the ampullary-periampullary region abutting head of the pancreas and confirmed on histopathological evaluation with immunohistochemistry.

Keywords: Pancreatic tumours, Exocrine tumours of pancreas, Solid pseudopapillary neoplasm

Corresponding Author

Sabina Khan, Professor, Department of Pathology, Hamdard Institute of Medical Sciences and Research, New Delhi, India.

Email: drsabina1@gmail.com
How to Cite this Article

To Browse

Khan S, Trisal M, Husain M, Khetrapal S, Hassan J, Jetley S. Solid Pseudopapillary Neoplasm of the Pancreas - A rare entity with emphasis on the differential diagnosis.. Trop J Pathol Microbiol. $2021 ; 7(1): 60-64$.

Available From

https://pathology.medresearch.in/index.php/jopm/ar

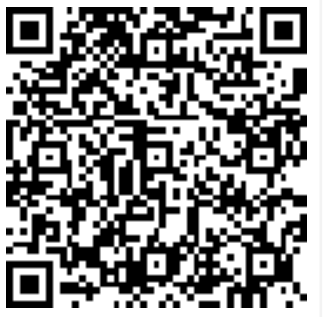
ticle/view/512
Manuscript Received 2021-02-05

Conflict of Interest No
Review Round 1 2021-02-15

Funding

Nil

Review Round 2
2021-02-20
Ethical Approval
Yes

Review Round 3

Accepted 2021-02-24

Plagiarism X-checker $8 \%$

(c) 2021 by Sabina Khan, Monal Trisal, Musharraf Husain, Shaan Khetrapal, Mohd. Jaseem Hassan, Sujata Jetley and Published by Siddharth Health Research and Social Welfare Society. This is an Open Access article licensed under a Creative Commons Attribution 4.0 International License https://creativecommons.org/licenses/by/4.0/ unported [CC BY 4.0] 


\section{Introduction}

The majority of the tumours of the exocrine pancreas include adenocarcinoma, intraductal papillary mucinous neoplasm, mucinous cystadenocarcinoma and acinar cell carcinoma.[1] They are aggressive tumors with a poor survival rate.

Solid pseudopapillary neoplasm develops from the exocrine pancreas and has low malignant potential. First described by Virginia Frantz in 1959, it constitutes 0.2 to $2.7 \%$ of all the neoplasms of the exocrine pancreas [2] and $5 \%$ of the cystic neoplasms. [3]

The diagnosis is suspected on imaging features demonstrating large encapsulated tumour with solid and cystic spaces. Solid pseudopapillary neoplasm occurs almost exclusively in young women and usually follow a benign course and are curable with excision.

SPNP pose a diagnostic challenge both clinically and radiologically due to their vague clinical presentation and varying degree of cystic degeneration, haemorrhage, and necrosis mimicking pseudocyst and even malignancy. [4] We present a case of a 32-year-old lady diagnosed with solid pseudopapillary neoplasm with emphasis on its clinicopathological features and histo- radiological findings.

\section{Case report}

A 32 years old post-cholecystectomy female presented in our hospital with a history of vomiting and fever for 15 days. There was yellowish discolouration of the eyes for 15 days and pain in the right upper quadrant of the abdomen. On examination, there was the presence of icterus. Perabdomen was soft, non-distended, non-tender with no organomegaly.

On MRCP, abrupt tapering of distal CBD with suspicious filling defect with dilated IHBR was seen. (Figure 1A). However, no growth was detected. ERCP showed distal CBD stricture and oedema in the papillary region. CA 19.9 levels were normal. LFT showed bilirubin $2.5 \mathrm{mg} / \mathrm{dl}$ and ALP level was $375 \mathrm{IU} / \mathrm{L}$. Abdominal CECT revealed a well-defined round soft tissue density measuring $2.4 \times 1.8 \mathrm{~cm}$ in the ampullary/Periampullary region abutting head and CBD with dilated IHBR. (Figure 1B)

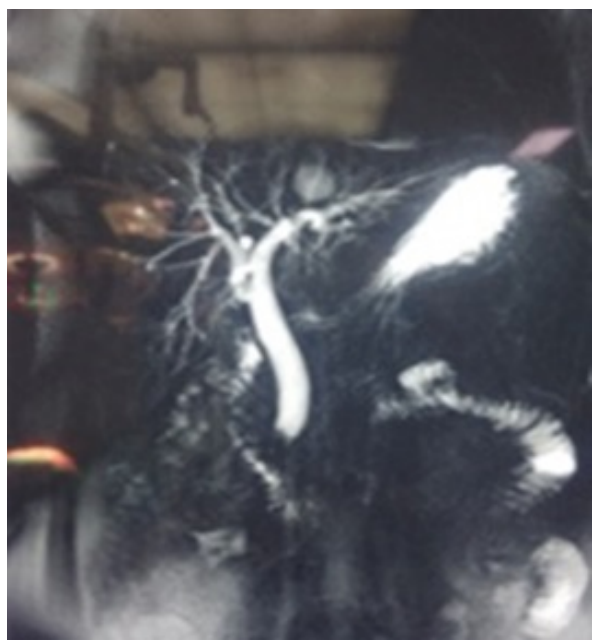

Figure 1A- MRCP image showing abrupt tapering of distal common bile duct with a suspicious filling defect with dilated intrahepatic biliary radicles.

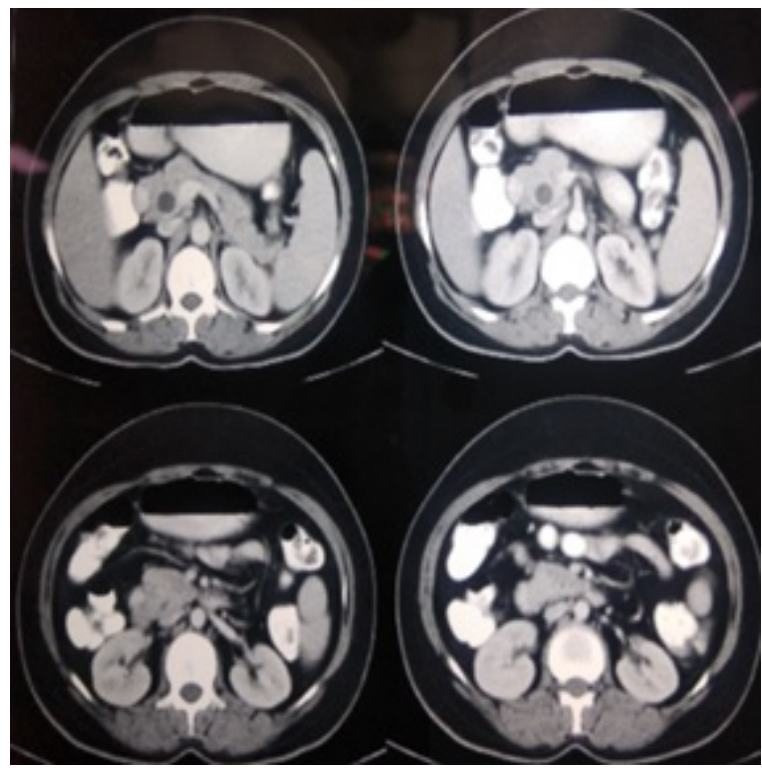

Figure 1B- CT scan image showing a well-defined pancreatic tumor with solid and cystic components.

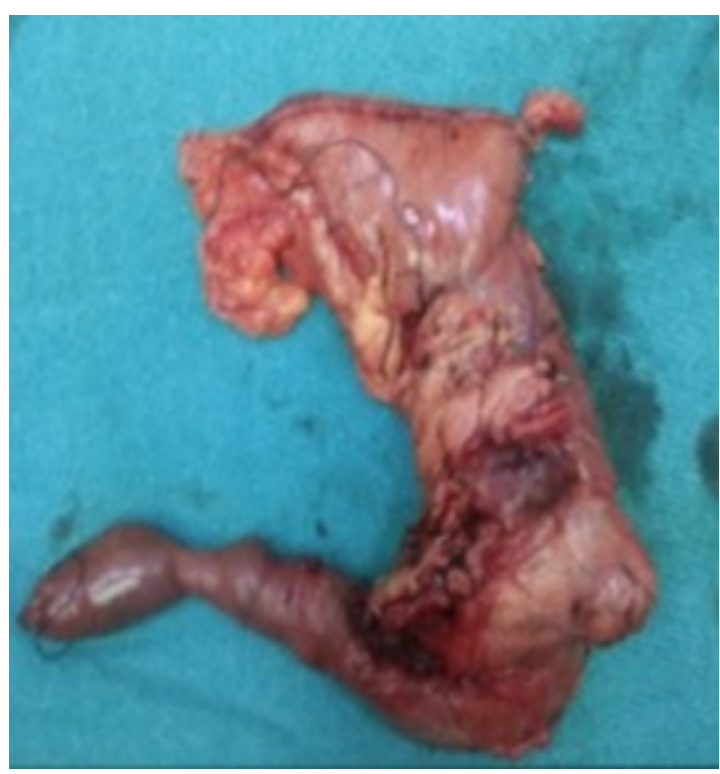


Figure 2A- Per-operative photograph of Whipple specimen showing a resected pancreatic head with the tumor along with the part of duodenum.

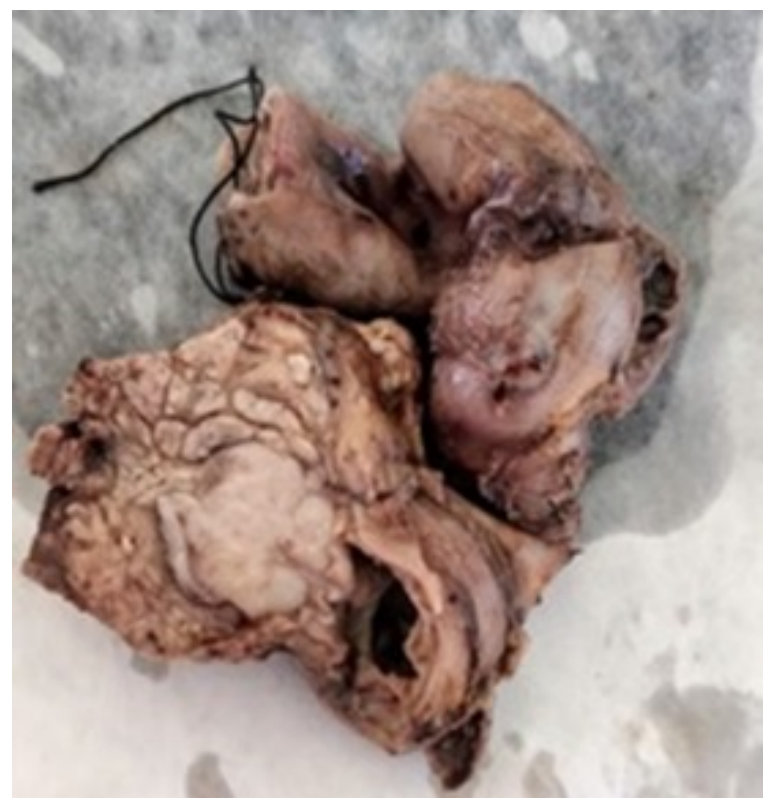

Figure 2B- Gross photograph showing encapsulated well-circumscribed tumor in the head of the pancreas with surrounding normal pancreatic tissue.

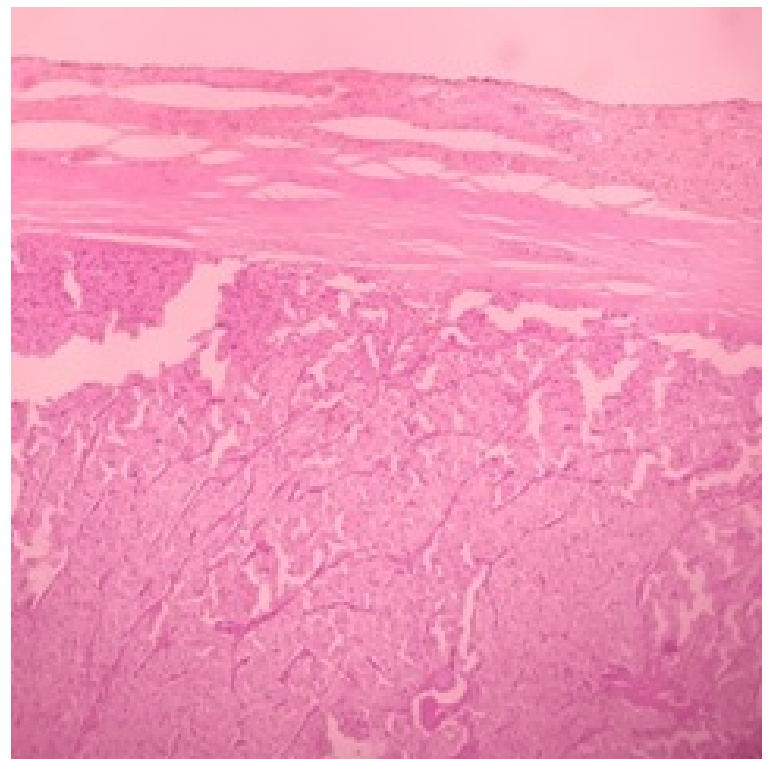

Figure 3A- Low power microphotograph showing well defined capsule with underlying solid nests of poorly cohesive cells forming a cuff surrounding blood vessels, resulting in a pseudopapillary architecture. ( $\mathrm{H} \& \mathrm{E}, 10 \mathrm{x})$.

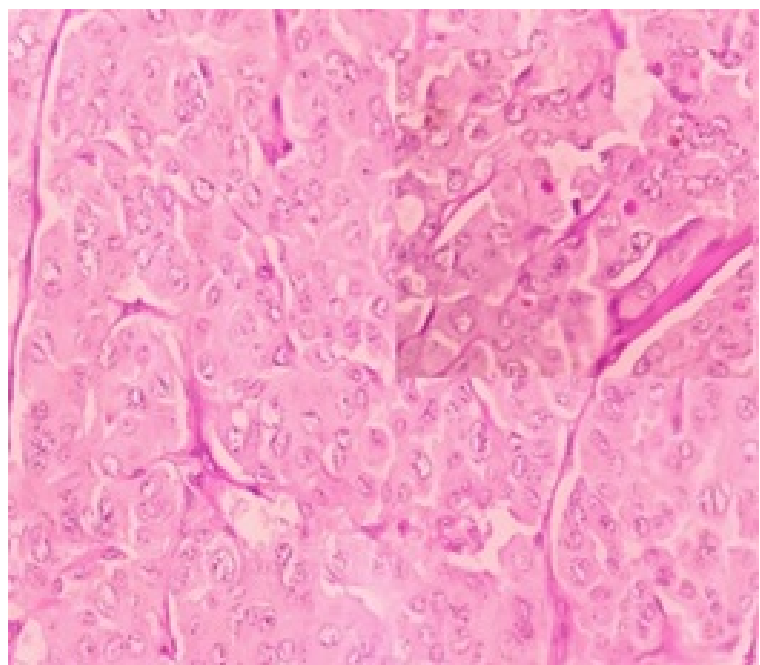

Figure 3B- High power view showing pseudopapillae with cells having round to oval nuclei, finely dispersed chromatin and eosinophilic cytoplasm ( $H \& E, 40 x$ ). Inset showing PAS positive hyaline globules in tumor cells.

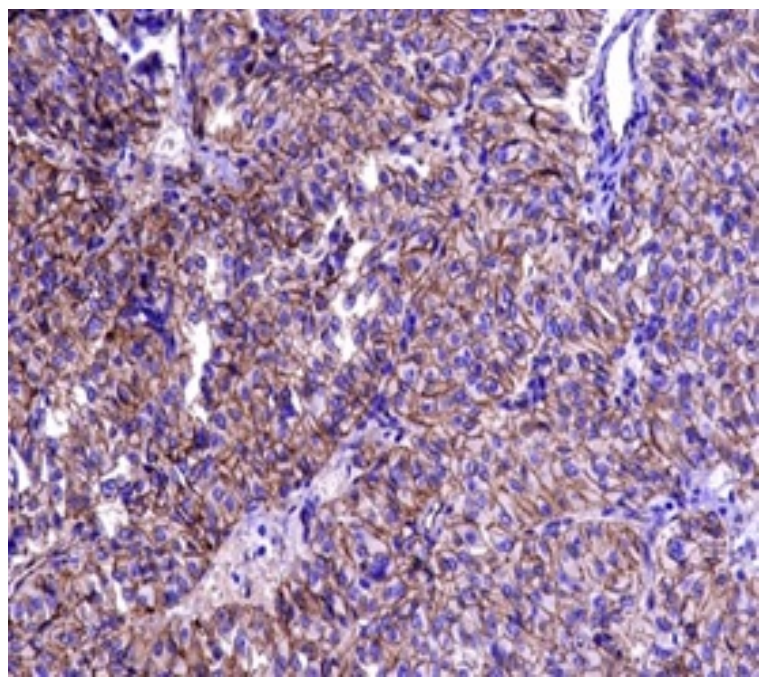

Figure 3C: Immunohistochemistry showing strong membranous positivity for beta-catenin. (IHC, 40x).

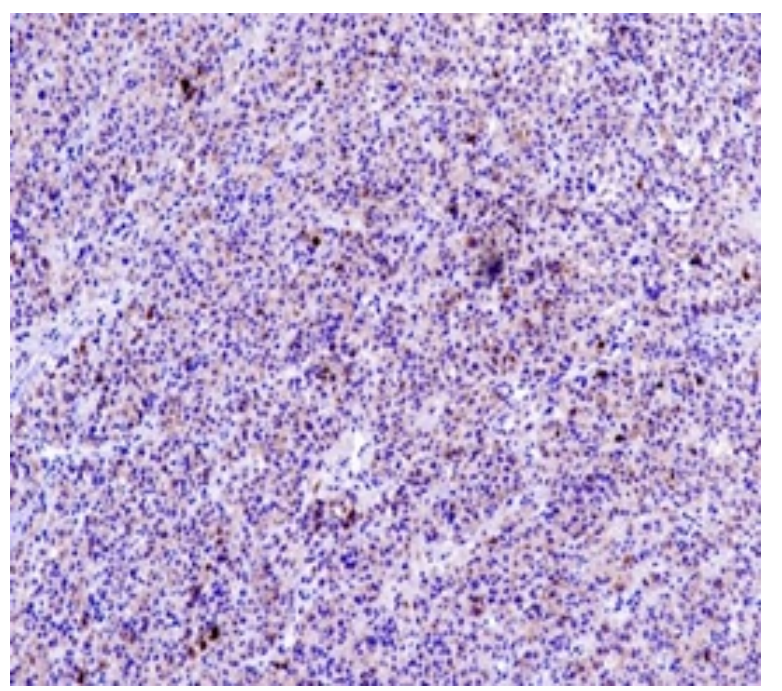


Figure 3D: Immunohistochemistry showing positivity for chromogranin in tumor cells. (IHC, $40 x)$.

Whipple's procedure was done and intraoperative findings showed a large approximately $3 \times 3 \mathrm{~cm}$ mass in the periampullary region in the head of the pancreas with grossly dilated CBD with multiple periportal and peripancreatic lymph nodes. (Figure 2A) Pancreaticoduodenectomy specimen, pericholedochal tissue and periportal lymph nodes were received in the histopathology lab for evaluation.

(Figure 2B) On histopathological examination, a well-demarcated, encapsulated tumor composed of uniform monotonous round to oval cells in solid sheets, cords and organoid pattern with the presence of pseudopapillae were seen. (Figure 3A). Cells exhibited mild pleomorphism with finely dispersed chromatin, eosinophilic cytoplasm and inconspicuous nucleoli. Few cells showed longitudinal grooving. (Figure 3B) Some of the tumor cells showed PAS-positive hyaline globules in their cytoplasm. (Figure 3B inset) No atypical mitosis was seen. All margins and all lymph nodes were free of tumor. Histopathological diagnosis of Solid pseudopapillary neoplasm of the pancreas was given and immunohistochemistry was advised to confirm the diagnosis and rule out histopathological mimics which include pancreatic endocrine neoplasm and acinic cell carcinoma. Immunohistochemical stains showed nuclear positivity for $\beta$-catenin (Figure 3C), and chromogranin (Figure 3D) and were negative for CD-10.

\section{Discussion}

The solid pseudopapillary neoplasm of the pancreas is a rare neoplasm of the exocrine pancreas almost exclusively found in females. The mean age for SPTP is 25-35 years and is very uncommon in males, children, and older females. [5]

SPTP is characterized by a long asymptomatic course and patients usually present with vague gastrointestinal symptoms. Therefore, it is not unusual that they are missed on initial evaluation and detected only when grown to a remarkable size. [6] This was seen in our case also when six months back initial radiological evaluation is done in our patient for gallbladder disease did not reveal any pancreatic abnormality. The clinical findings and the radiological features of SPNP can help in making the correct diagnosis and in differentiating these lesions from other pancreatic neoplasms.
Abdominal ultrasound and computed tomography (CT) scan usually demonstrate a large, wellencapsulated mass with both solid and cystic components causing displacement of nearby structures. [7]

Grossly, the tumour ranges from 0.5 to $34.5 \mathrm{~cm}$ with a mean diameter of $6 \mathrm{~cm}$ and are well defined, encapsulated with a variable amount of solid and cystic patterns. In our case, the lesion measured approximately $3 \mathrm{~cm}$ and was very wellcircumscribed, sharply delineated from the surrounding parenchyma. Histologically, solid nests of poorly cohesive cells form a cuff around the blood vessels, resulting in a pseudopapillary architecture.

Large intracytoplasmic hyaline globules, perinuclear vacuoles and characteristic longitudinal grooves are seen. These globules are typically periodic acidSchiff (PAS) positive and diastase resistant and highly characteristic for diagnosis of SPNP as were seen in our case too. A point mutation in exon 3 of the $\beta$-catenin gene (CTNNB1) is present in more than $90 \%$ of the patients followed by involvement of oncogenic genes such as Myc and Cyclin D1.[8]

These changes can be detected by strong nuclear staining of $\beta$-catenin and cyclin D1, and by loss of E-cadherin membranous staining in these tumor cells. Almost $80 \%$ of all cystic lesions of the pancreas are pseudocysts followed by serous cystadenoma, pancreatic mucinous cystic neoplasm (PMCN), intraductal papillary mucinous neoplasm (IPMN), cystic pancreatic neuroendocrine neoplasm (PNN), and SPNP. All these entities form the clinical and radiological differential diagnosis.[9]

Histological differential diagnosis include Pancreatic neuroendocrine neoplasm, acinar cell carcinoma and pancreatoblastoma. Pancreatic neuroendocrine neoplasm (PNN) is a major challenge in the differential diagnosis of SPTP because the morphological and immunohistochemical features overlap.

Distinguishing features are small to medium-sized cells with uniform nuclei and finely granular chromatin (salt and pepper appearance), arranged in nests, organoid and trabecular arrangement. PNN are positive for neuroendocrine markers and negative for $\beta$-catenin.

However our case was positive for $\beta$-catenin and chromogranin too thus ruling out PNN. SPTP cells are weakly positive for antibodies directed against chromogranin in $38 \%$ of cases in some reports. 
Acinar cell carcinoma (ACC) differs from SPTP by its prominent acinar formation, cells with finely granular cytoplasm and positivity for pancreatic enzymes with variable staining for $\beta$-catenin. In our case tumor cells were negative for CD10 and trypsin. Pancreatoblastoma shows primitive pancreatic elements with acinar, ductal and neuroendocrine differentiation; also squamoid corpuscles; more common in children younger than 10 years; positive for $\beta$-catenin (80\%), neuroendocrine markers and pancreatic enzymes(trypsin, chymotrypsin and lipase). Diffuse immunostaining for $\beta$-catenin has been found in the cytoplasm and nuclei of SPNP, in contrast to the predominantly membranous reactivity in PNN and ACC (25\% may show nuclear staining), which may be helpful in distinguishing between SPTP and such neoplasms. [10]

\section{Conclusion}

Through this case report, we wish to emphasize that a high index of suspicion is necessary to diagnose Solid pseudopapillary neoplasm as it carries a good prognosis and its diagnosis should always be considered in a young female presenting with a pancreatic mass. Moreover, the histopathologist needs to be aware of its histopathological mimics with judicious use of a select panel of immunostains for its definitive diagnosis.

\section{Reference}

01. Hruban RH, Pitman MB, Klimstra DS. Tumours of the Pancreas. Washington, DC: American Registry of Pathology. Atlas of Tumor Pathology. 2007; 4th series, fascicle 6 [Crossref]

02. Papavramidis T, Papavramidis S. Solid pseudopapillary tumors of the pancreas: a review of 718 patients reported in the English literature. J Am Coll Surg. 2005;2:965-72.

[Crossref]

03. Parra Herran CE, Garcia MT, Herrera L, Bejarano PA. Cystic lesions of the pancreas: clinical and pathologic review of cases in a five-year period. J Pathol. 2010;11:358- 64.

[Crossref]

04. Yang F, Fu DL, Jin C, Long J, Yu XJ, Xu J et al. Clinical experiences of solid pseudopapillary tumors of the pancreas in China. J Gastroenterol Hepatol. 2008;23:1847-51.

[Crossref]
05. Goh BK, Tan YM, Cheow PC, Chung AY, Chow PK, Wong WK et al. Solid Pseudopapillary tumor of pancreas: an updated experience. J Surg Oncol. 2007;95:640-4.

[Crossref]

06. Madan AK, Weldon CB, Long WP, Johnson D, Raafat A. Solid and papillary epithelial neoplasm of the pancreas. J Surg Oncol. 2004;85:193-8. [Crossref]

07. Salvia R, Bassi C, Festa L. Clinical and biological behavior of pancreatic solid pseudopapillary tumors: report on 31 consecutive patients. J Surg. Oncol. 2007;95:304 [Crossref]

08. Yu PF, Hu ZH, Wang XB. Solid pseudopapillary tumor of the pancreas: a review of 553 cases in Chinese literature. World J Gastroenterol. 2010;16:1209-14.

[Crossref]

09. Huang HL, Shih SC, Shang WH. Solidpseudopapillary tumor of the pancreas: clinical experience and literature review. World J Gastroenterol. 2005;11:1403-9.

[Crossref]

10. Li L, Li J, Hao C, Zhang C, Mu K, Wang Y, Zhang T. Immunohistochemical evaluation of solid pseudopapillary tumors of the pancreas: the expression pattern of CD99 is highly unique. Cancer Lett. 2011; 310:9-14.

[Crossref] 